\title{
Saúde mental de agentes penitenciários de um presídio catarinense
}

\author{
Mental health of penitentiary agents at a prison in Santa Catarina State, Brazil
}

Aline Bonez ${ }^{[a]}$, Elisamara Dal Moro ${ }^{[a]}$, Scheila Beatriz Sehnem ${ }^{[b]}$

\footnotetext{
[a] Acadêmicas do curso de Psicologia da Universidade do Oeste de Santa Catatina (Unoesc), câmpus Joaçaba, Joaçaba, SC - Brasil, e-mails: aline_bonez@yahoo.com.br elydalmoro@yahoo.com.br

${ }^{[b]}$ Psicóloga, mestre em Educação pela Universidade do Oeste de Santa Catarina (Unoesc), professora do curso de Psicologia da mesma instituição, Joaçaba, SC - Brasil, e-mail: scheila.menezes@unoesc.edu.br
}

Recebido: $16 / 12 / 2011$ Received: 12/16/2011

Aprovado: $17 / 04 / 2012$ Approved: 04/17/2012

\begin{abstract}
Resumo
A segurança é um dos temas de grande relevância para a sociedade, sendo, o sistema prisional, um dos órgãos públicos que devem empreender esforço para mantê-la. 0 agente prisional é o profissional responsável pela segurança interna de um presídio e pela ordem entre os presos, desempenhando uma função de alto risco, uma vez que estão em contato direto com detentos e expostos a diversas situações geradoras de estresse. Sendo assim, esta pesquisa objetiva descrever as variáveis que interferem na saúde mental dos agentes penitenciários, envolvendo o perfil sociodemográfico, as condições de saúde mental e os níveis de estresse desses profissionais; tais dados foram obtidos mediante Escalas Beck, ISSL e um questionário semiestruturado elaborado pelas pesquisadoras. Participaram da pesquisa 19 sujeitos entre 22 e 69 anos de idade, com prevalência do sexo masculino e escolaridade considerada alta, uma vez que $21,05 \%$ dos sujeitos concluíram o ensino médio, $21,05 \%$ apresentavam ensino superior incompleto e $21,05 \%$ ensino superior completo. Os dados revelam que $100 \%$ dos sujeitos não possuem desesperança e depressão, não havendo ideação suicida, 5,26\% apresentam grau mínimo de ansiedade e 31,57\% se encontram na fase de resistência do estresse. Segundo os resultados obtidos nesta pesquisa, percebe-se que esses agentes penitenciários possuem condições de saúde mental relativamente boas; isso talvez possa ser explicado pelo fato de os profissionais entrevistados possuírem tempo de serviço considerado baixo - 21,05\% dos sujeitos possuem tempo de serviço inferior a um ano e $42,10 \%$ entre um e cinco anos.
\end{abstract}

Palavras-chave: Saúde mental. Estresse. Penitenciária.

\section{Abstract}

Security is a topic of great relevance to society, and the prison system is one of the public agencies responsible for maintaining it. The prison agent is the professional responsible for internal security in a prison and also responsible for the order among the prisoners, carrying a high risk due to being in direct contact with prisoners and exposed to different situations which induce stress. Being thus this research objectified to describe the sociodemographic profile, analyze the conditions of mental health and evaluate the level of stress of these professionals, data which that had been gotten by means of psychological instruments Scales Beck and ISSL and a semi-structuralized questionnaire, elaborated by the researchers. Nineteen individuals, from 22 to 69 years-old, with prevalence of sex masculine and considered with high school level participated of this research. The data reveal that $100 \%$ of the

Psicol. Argum. 2013 jul./set., 31 (74), 507-517 
subjects do not possess hopelessness and depression having the absence of suicidal ideation, 5.26\% present minimum degree of anxiety and $31.57 \%$ are in the Phase of Resistance of Stress. According to resulted gotten in this research, realizes that these penitentiary agents possess relatively good conditions of mental health, fact that, perhaps, can be explained by possessing time of service considered low, being that $21.05 \%$ of the citizens possess time of service inferior to one year and $42.10 \%$ from one to five years.

Keywords: Mental health. Stress. Penitentiary.

\section{Introdução}

A cada dia a violência no Brasil aumenta de forma considerável (Silva, 2011, p. 2), tornando a segurança um dos temas de grande relevância para a população e para os órgãos públicos do país. Um dos profissionais envolvidos nesse contexto é o agente prisional. Apesar desse cenário, são raros os estudos que se preocupam com a saúde desses agentes responsáveis pela segurança penitenciária. Partindo dessa premissa e considerando que esses profissionais desempenham uma função de alto risco, uma vez que estão em contato direto com os detentos e expostos a diversas situações geradoras de estresse, propõe-se a investigação das condições de saúde mental de agentes penitenciários, verificando o perfil sociodemográfico destes e o nível de estresse decorrente da atividade laboral.

O conceito de saúde mental, de acordo com a Organização Mundial de Saúde [OMS] (2002, p. 30) tem o mesmo princípio amplo que a saúde, não sendo considerada apenas ausência de doenças, mas um completo bem-estar físico, psíquico e social. Complementando essa visão, a Mental Health: report of the Surgeon General (1999 citado por Sadock \& Sadock, 2007, p. 31) define saúde mental como “... um estado de bom desempenho da função mental, resultando em atividades produtivas, cumprindo o relacionamento com outras pessoas, e a capacidade de adaptação à mudança e a lidar com a diversidade”.

É fundamental analisar as condições de saúde mental dos agentes penitenciários, pois o trabalho desses profissionais requer muita responsabilidade e empenho, além de exigir "... perfil adequado quanto à sua postura..." diante dos presos (Ramos \& Esper, 2007, p. 58). Ademais, Rocha (2003, pp. 15-20) relata que a atividade desempenhada pelos agentes mantém contato direto com os aprisionados, tendo a finalidade de prezar pela segurança e reeducação destes e, ao mesmo tempo, impedi-los de sair daquele ambiente, vigiando-os continuamente. Os agentes são os únicos intermediários entre os reclusos e a sociedade, o que os obriga a conviverem e a manterem relacionamentos com dois mundos sociais e culturais distintos. Para Santos (2007, p. 2), não há uma possibilidade de desligamento total por parte dos funcionários que trabalham nessas instituições em razão do ambiente atípico, que é penoso, perigoso e insalubre; eles convivem com indivíduos das mais variadas personalidades, contatando diversas experiências que tendem a ser pouco positivas.

As atividades desempenhadas pelos agentes, somadas às péssimas condições oferecidas pelo sistema prisional brasileiro e o desrespeito e descaso da sociedade exercem influência não somente na saúde física, mas também no estresse e sofrimento psíquico dos agentes penitenciários. Segundo Ramos e Esper (2007, p. 24), “... estas condições combinadas a um excesso crônico de trabalho tornam a profissão ainda mais árdua e difícil de ser desempenhada...".

Nesse sentido, o estresse pode trazer consequências para as diversas áreas do funcionamento humano, caso o indivíduo não tenha estratégias adequadas para lidar com os desafios que enfrenta (Cipriano, 2004, p. 162). Segundo Mendoza, Medeiro e Costa (2007, p. 95):

O estresse, relacionado ao trabalho, é definido como situações em que a pessoa percebe seu ambiente laboral como ameaçador de suas necessidades de realização profissional, ou de sua saúde física ou mental, prejudicando a interação da pessoa com os outros e com o ambiente de trabalho, na medida em que este ambiente contém demandas excessivas a ela, ou que ela não dispõe de recursos adequados para enfrentar tais situações.

De acordo com Spielberger (1981 citado por Rezende Neto, 2004, p. 94), o estresse é o processo responsável pelo surgimento de um estado de ansiedade; pode ser iniciado por estímulos externos 
que se caracterizam como ameaçadores, evocando uma reação do organismo.

A ansiedade causada pelo fato de o agente penitenciário estar diariamente submetido a situações de pressão e desconforto, a desvalorização ou falta de reconhecimento da população em geral sobre o seu papel social, e a sobrecarga de atividades acarretam na conversão dos sintomas psicológicos para o corpo, como maneira de manifestar essa frustração. 0 corpo torna-se alvo de todos os sofrimentos, gerando uma degradação da integridade física e psíquica.

Para Lancman, Sznelwar e Jardim (2006, p. 134), "o trabalho e o reconhecimento pelo esforço para fazê-lo acontecer é um dos principais alicerces para a construção da saúde mental, caso contrário, pode ser desencadeado um processo de elevado nível de sofrimento". Portanto, justifica-se a inserção da presente pesquisa nesta temática, uma vez que é possível elaborar estratégias de intervenção de cunho preventivo na saúde mental dos agentes penitenciários.

\section{Indicacão dos procedimentos metodológicos e técnicos}

A pesquisa tem natureza descritiva com abordagem qualiquantitativa. Fizeram parte deste estudo 19 indivíduos que exerciam atividades em uma Unidade Prisional do Oeste de Santa Catarina, sendo três do sexo feminino e 16 do sexo masculino. Dos sujeitos, nove eram agentes penitenciários concursados e nove eram policiais militares aposentados, contratados para desempenhar as funções de agente penitenciário. Durante a coleta de dados, incluiu-se como sujeito da pesquisa um funcionário da instituição, que é contratado como recepcionista, mas que desempenha atividades próprias dos agentes penitenciários, devido à falta de profissionais na área.

Para análise da saúde mental dos participantes, foram utilizados os seguintes instrumentos: Escalas Beck, que é o conjunto de quatro medidas escalares - Inventário de Depressão (BDI), Inventário de Ansiedade (BAI), Escala de Desesperança (BHS) e Escala de Ideação Suicida (BSI) - desenvolvidas por Beck e seus colegas no Center Cognitive Therapy (CCT) da Universidade da Pensylvania, na Philadelphia, Estados Unidos. O BDI é uma escala de autorrelato, com 21 itens, cada um com quatro alternativas, subentendendo graus crescentes de gravidade da depressão (Willians, Brarlow \& Agras, 1972 citado por Cunha,
2001, p. 4). 0 BAI é constituído por 21 itens, que são afirmações referentes aos sintomas de ansiedade e que devem ser avaliados pelo sujeito como referência a si, em uma escala de quatro pontos que refletem os níveis de gravidade dos sintomas. 0 BHS é uma escala dicotômica, que engloba 20 itens, consistindo em afirmações que envolvem cognições sobre desesperança avaliando a extensão das expectativas negativas em relação ao futuro. O BSI é uma versão de autorrelato constituído por 21 itens. Os primeiros 19 itens refletem gradações da gravidade dos desejos suicidas. Os dois últimos itens fornecem importantes subsídios a respeito do paciente quanto ao número de tentativas de suicídio e severidade da intenção de morrer (Cunha, 2001, pp. 4-9).

No que se refere ao estresse, utilizou-se o Inventário de Sintomas de Stress para Adultos de Lipp (ISSL) desenvolvido por Marilda Novaes Lipp. Esse inventário visa a identificar, de modo objetivo, a sintomatologia que o paciente apresenta, avaliando se este possui sintomas de estresse e o tipo de sintoma existente (somático ou psicológico) e a fase em que se encontra (Lipp, 2000, p. 10).

Além dessas escalas, foi elaborado pelas pesquisadoras um questionário cujo objetivo é descrever o perfil dos agentes penitenciários com itens referentes a questões sociodemográficas.

0 projeto foi submetido à apreciação do Comitê de Ética em Pesquisa (CEP) da Unoesc, câmpus de Joaçaba, onde foi aprovado sob o número de protocolo $013 / 2010$.

\section{Análise e discussão dos dados}

\section{Perfil sociodemográfico dos agentes penitenciários}

0 agente penitenciário exerce um importante serviço público de alto risco, o que exige um perfil adequado quanto à sua postura diante dos presos; requer compromisso com a instituição à qual serve, trabalhando com dignidade e ética e, acima de tudo, respeitando os seres humanos que ali estão confinados (Ramos \& Esper, 2007, p. 58).

Para o levantamento das informações referentes ao perfil sociodemográfico dos agentes penitenciários foi utilizado um questionário semiestruturado com perguntas relacionadas aos itens sexo, faixa etária, estado civil, nível de escolaridade, entre outros, como é possível observar na Tabela 1.

Psicol. Argum. 2013 jul./set., 31 (74), 507-517 
Tabela 1 - Descrição da amostra em relação a aspectos demográficos

\begin{tabular}{lll}
\hline Variáveis & \multicolumn{2}{l}{ Resultados } \\
& $\mathbf{n}$ & $\%$ \\
\hline Faixa etária & 3 & 15,78 \\
$20-29$ & 4 & 21,05 \\
$30-39$ & 3 & 15,78 \\
$40-49$ & 9 & 47,36 \\
Mais de 50 & & \\
Sexo & 16 & 84,21 \\
Masculino & 3 & 15,78 \\
Feminino & & \\
Estado civil & 3 & 15,78 \\
Solteiro(a) & 12 & 63,15 \\
Casado(a) & 3 & 15,78 \\
União estável & 1 & 5,26 \\
Separado(a) & & \\
Nível de escolaridade & 2 & 10,52 \\
Ensino fundamental incompleto & 3 & 15,78 \\
Ensino fundamental completo & 3 & 10,52 \\
Ensino médio incompleto & 2 & 21,05 \\
Ensino médio completo & 4 & 21,05 \\
Ensino superior incompleto & 4 & 21,05 \\
Ensino superior completo & 4 & \\
\hline
\end{tabular}

Fonte: Dados da pesquisa.

Segundo os dados, verifica-se que os participantes da pesquisa são predominantemente do sexo masculino (84,21\%), devido à existência de uma quantidade maior de homens infratores nesta unidade prisional, pois o detento somente pode ser vigiado por um agente do mesmo sexo (Fernandes et al., 2002, p. 810). Segundo a Lei de Execução Penal (LEP) n. 7.210 (1984), em seu Art. $83 \S 3^{\circ}$ os estabelecimentos destinados a apenados do sexo feminino devem ser exclusivamente assistidos por agentes do mesmo sexo. Nenhuma lei específica foi encontrada em relação aos agentes do sexo masculino, mas fica implícito nos artigos da Lei supracitada.

A idade dos sujeitos varia de 22 a 69 anos, com média 45,6. Entretanto, o maior percentual encontra-se na faixa etária acima de 50 anos $(47,36 \%)$, pois grande parte dos agentes penitenciários que atuam na instituição são policiais militares da reserva já aposentados, contratados para suprir a defasagem de agentes penitenciários. De acordo com a literatura pesquisada (Fernandes et al., 2002;
Ramos \& Esper, 2007), percebe-se que há uma concentração de agentes penitenciários na faixa etária dos 30 a 50 anos. Todavia, é importante ressaltar que os estudos referentes à saúde desse público-alvo são relativamente escassos.

Quanto à situação conjugal, os resultados apontam que $63,15 \%$ dos participantes são casados, o que pode ser justificado pela faixa etária em que se encontram. Da mesma forma, essa faixa etária mais alta, composta principalmente por policiais militares aposentados que não necessitam fazer concurso para atuar como agente, explica o fato de alguns sujeitos não possuírem o nível escolar mínimo exigido nos concursos destinados ao cargo, o ensino médio completo. Apesar disso, a escolaridade apresentada pelo grupo é considerada alta, já que $12(63,15 \%)$ concluíram o ensino médio, e oito $(42,10 \%)$ destes ingressaram no ensino superior. Dos sujeitos que concluíram o ensino superior, $75 \%$ possuem pós-graduação. É interessante observar o relato do Sujeito 19 "...pretendo galgar carreiras de outros níveis do Poder Judiciário e mesmo dentro da esfera da Segurança Pública futuramente, após formado no curso de Direito"; e também o relato do Sujeito 11, que afirma se sentir satisfeito com a profissão; "Principalmente pelo fato de ser especialista em Direito Penal e trabalhar no ramo". Nota-se que há o interesse de alguns agentes penitenciários em seguir sua carreira profissional no âmbito de segurança pública, ao contrário do que demonstra a pesquisa de Ramos e Esper (2007, p. 65), realizada em uma penitenciária feminina em Curitiba, onde $75,76 \%$ do grupo pesquisado apresentam nível médio de ensino e não se sentem motivados a cursar o ensino superior mesmo que a remuneração seja melhor. Segundo os autores, essa desmotivação é decorrente do trabalho estressante e cansativo de uma jornada de 12 horas diárias. Já na pesquisa de Fernandes et al. (2002, p. 811) discute-se a questão de que a existência de agentes que possuem nível superior de escolaridade é reflexo da dificuldade de inserção destes no mercado de trabalho, buscando tal atividade como uma situação provisória.

Ainda em relação ao perfil sociodemográfico incluem-se fatores referentes às condições de trabalho que interferem na saúde mental dos agentes, principalmente as variáveis "tempo de serviço", "carga horária" e "remuneração" (Tabela 2).

Na Tabela 2 é possível verificar que o tempo de serviço dos sujeitos como agente penitenciário é relativamente baixo, uma vez que $21,05 \%$ possuem menos de um ano de serviço, $42,10 \%$ de 1 a 5 anos e $36,84 \%$ 
Tabela 2 - Dados referentes à atividade exercida

\begin{tabular}{lcc}
\hline \multirow{2}{*}{ Variáveis } & Resultados \\
& n & \% \\
\hline Tempo de serviço (anos) & 4 & 21,05 \\
0 a 1 & 8 & 42,10 \\
1 a 5 & 7 & 36,84 \\
> 5 & & \\
Transferência de unidade prisional & & 42,10 \\
Sim & 8 & 57,89 \\
Não & 11 & \\
Carga horária & & \\
Regime de turno 24/72 h & 17 & 89,47 \\
40 h semanais (8 h/dia) & 1 & 5,26 \\
30 h semanais 6 h/dia & 1 & 5,26 \\
Hora extra & & \\
Sim & 10 & 52,63 \\
Não & 9 & 47,36 \\
Salários-mínimos & & \\
1 a 2 & 10 & 52,63 \\
3 a 4 & 5 & 26,31 \\
5 ou mais & 15 & 78,94 \\
Satisfação profissional & 3 & 15,78 \\
Sim & 4,25 \\
Não & & \\
Indeciso & & \\
\hline & & \\
\hline
\end{tabular}

Fonte: Dados da pesquisa.

mais de 5 anos de profissão independente de transferências de unidades prisionais. 0 tempo de serviço é um dos fatores que podem influenciar no aparecimento de sintomas psicológicos e físicos; também o excesso de trabalho e a constante mudança de locais estão entre esses fatores, o que exige adaptação contínua. Segundo Ramos e Esper (2007, p. 66), quanto maior o tempo de serviço, maior a carga de estresse devido ao clima tenso do local de trabalho, propiciando o surgimento de sentimentos de ansiedade e tristeza crônica, tornando o indivíduo receoso com sua vida.

Do total de participantes, $42,10 \%$ já foram transferidos de unidade prisional; $50 \%$ destes o fizeram por mais de uma vez. Quanto à carga horária, 89,47\% dos agentes penitenciários realizam regime de turno 24 horas de trabalho por 72 horas de folga, o que é determinado pelo Plano Diretor da Secretaria de Segurança Pública do Estado de Santa Catarina, e os outros $10,52 \%$ trabalham diariamente. Porém, mesmo trabalhando em regime de turno, 52,63\% dos sujeitos fazem horas extras em razão do número insuficiente de funcionários.

Para Lopes (2002, p. 6), a superlotação prisional e a carência de funcionários no setor de segurança das prisões intensificam o desgaste físico e mental dos agentes, à medida que há uma sobrecarga de atividades juntamente com a baixa remuneração e o alto índice de transferências. Essa sobrecarga e instabilidade do local, com o passar do tempo, influenciam o comportamento de grande parte dos agentes, comprometendo não apenas sua subjetividade, como também seu trabalho de reeducador social. Em pesquisa realizada por Rumin (2006, p. 573), observa-se que das 200 vagas oferecidas para agentes penitenciários na instituição pesquisada, somente 20 eram ocupadas por esses profissionais, o que gera sobrecarga de trabalho. Esse cenário aumenta o risco de rebeliões e tentativas de fuga pela vulnerabilidade da segurança interna, uma vez que isso intensifica o nível de estresse e ansiedade dos profissionais, prejudicando o desempenho de suas funções.

Os dados demonstram a baixa remuneração dos entrevistados; mais da metade $(52,63 \%)$ deles recebe entre um e dois salários-mínimos, 26,31\% recebem entre três e quatro salários-mínimos, e 21,05\% cinco ou mais salários-mínimos. Segundo informações obtidas com a gerência da instituição, os critérios para a remuneração dos agentes penitenciários são estabelecidos a partir do grau de escolaridade e do tempo de serviço.

Analisando os dados obtidos, há uma coerência no total de sujeitos com ensino superior completo e com o número de sujeitos que recebem mais de cinco salários-mínimos, porém, há uma discrepância com a variável tempo de serviço, do mesmo modo que o número de sujeitos com nível de escolaridade médio completo e superior incompleto não condiz com o número de sujeitos que recebem de três a quatro salários-mínimos.

Os resultados obtidos relacionados à satisfação quanto à profissão revelam que 15 (78,94\%) estão satisfeitos, 15,78\% encontram-se insatisfeitos e 5,26\% indecisos. Dos 15 sujeitos que se dizem satisfeitos, $73,33 \%$ afirmam que a realização financeira é um dos fatores que contribuem para a satisfação profissional. Observe-se o relato do Sujeito 19: “... sinto-me satisfeito com minha profissão atualmente, pois através dela consigo prover minhas necessidades e de minha família". Entretanto, os sujeitos que se encontram insatisfeitos

Psicol. Argum. 2013 jul./set., 31 (74), 507-517 
utilizam como justificativa as atividades perigosas, como relata o Sujeito 10 "... pois se trata de uma profissão que envolve muitos riscos".

Em pesquisa realizada por Ramos e Esper (2007, p. 69), é notório que $66,67 \%$ dos agentes penitenciários entrevistados se encontram indecisos em relação à profissão - 18,18\% sentem-se satisfeitos, e $15,15 \%$ dizem-se insatisfeitos. Segundo os autores, os motivos de desmotivação dos agentes diante do trabalho podem estar relacionados à falta de valorização profissional, más condições de trabalho e carga horária inadequada (de 12 horas de trabalho por 36 horas de folga, considerada muito cansativa).

De acordo com alguns autores, como Zanin e Oliveira (2006, p. 4), a profissão dos agentes responsáveis pela segurança penitenciária é muito desvalorizada no Brasil, sendo os salários baixíssimos e as condições de trabalho péssimas, o que possivelmente interfere na satisfação do agente em relação às suas atividades.

\section{Saúde mental dos agentes penitenciários}

Falar em saúde implica pensar no homem como totalidade, envolvendo fatores biológicos, psicológicos e sociológicos e, ao mesmo tempo, em todas as condições de vida que visam a propiciar-lhe bem-estar físico, mental e social (Bock, Furtado \& Teixeira, 2002, p. 357).

Saúde mental para Chaplin (1989 citado por Rosa, 2007, p. 27) é um estado de boa adaptação, com sensação subjetiva de bem-estar, onde o indivíduo exerce seus talentos e aptidões. É regida pela Lei n. 10.216 (2001), a qual privilegia o oferecimento de tratamento em serviços de base comunitária e dispõe sobre proteção e direito às pessoas com transtornos mentais. Entre as constantes variáveis que englobam a saúde mental, esta pesquisa aborda ansiedade, desesperança, depressão e ideação suicida, expostas na Tabela 3. Esses itens são avaliados pelo instrumento Escalas Beck, traduzido para o português por Cunha (2001).

No que se refere à variável ansiedade, percebe-se que a maioria $(94,73 \%)$ dos agentes penitenciários entrevistados apresenta nível mínimo; conseguem conter suas emoções e/ou angústias e controlar sua ansiedade diante de um fato não concreto. É normal e até esperado que o ser humano apresente alguns sintomas de ansiedade perante situações perigosas
Tabela 3 - Dados referentes à saúde mental

\begin{tabular}{lcc}
\hline Variáveis & Resultados & \\
& n & \% \\
\hline Grau de ansiedade & 18 & 94,73 \\
Mínimo & 1 & 5,26 \\
Leve & - & - \\
Moderado & - & - \\
Grave & & \\
Grau de desesperança & 19 & 100 \\
Mínimo & - & - \\
Leve & - & - \\
Moderado & - & - \\
Grave & & \\
Grau de depressão & 19 & 100 \\
Mínimo & - & - \\
Leve & - & - \\
Moderado & - & - \\
Grave & & \\
Ideação suicida & 19 & 100 \\
Não & - & - \\
Sim & & \\
\hline
\end{tabular}

Fonte: Dados da pesquisa.

ou que criem expectativas quanto a algo que está para ocorrer.

Entretanto, é possível observar que existem indícios de ansiedade patológica, sendo esta representada por 5,26\% da população pesquisada. Apesar do baixo percentual apresentado, este é um dado importante a ser considerado, pois diante do ambiente estressor a que esses sujeitos estão expostos, é possível que o quadro evolua, assim como outros agentes penitenciários também venham a apresentar esses sintomas ansiosos.

Para Sadock e Sadock (2007, p. 630), ansiedade é uma sensação desagradável que indica um perigo iminente, capacitando o indivíduo a tomar medidas para a resolução do problema, por vezes surge com sintomas autônomos como cefaleia, perseguição, palpitações, aperto no peito, leve mal-estar epigástrico e inquietação, indicados pela incapacidade de ficar sentado ou em pé quieto por muito tempo. Complementando o conceito, Hanns (1996, p. 65), nos diz que é uma “... expectativa inquieta por algo que ocorrerá, sentimento de ânsia no sentido de se sentir oprimido, angustiado". 
Em pesquisa realizada por Chies (2001 citado por Lund, Nedel, Nedel, Biguetti \& Castilhos, 2009, p. 3) no Presídio Regional de Pelotas é notório que 63,3\% dos agentes penitenciários entrevistados se sentem ansiosos e $46,67 \%$ inseguros. Tais dados diferem dos resultados da presente pesquisa, pois segundo as respostas obtidas na pergunta "Como você se sente diante do preso?" os entrevistados demonstram certo grau de superioridade e receio, como se percebe no relato de alguns sujeitos: "Sinto-me superior a eles, nunca inferior. Prestei concurso e estou preparado para trabalhar com os presos" (Sujeito 1); "Como uma pessoa normal, representante do Estado que tenta ressocializá-lo e discipliná-lo dentro de suas possibilidades reais" (Sujeito 14); "Como uma autoridade, que impõe respeito" (Sujeito 4). Já o Sujeito 5 demonstra o sentimento de insegurança em seu relato "... Confio nele desconfiando, não se sabe o que ele pensa". A superioridade e o receio apresentados nesses relatos podem ser interpretados de acordo com a teoria psicanalítica de mecanismos de defesa ${ }^{1}$ utilizados por estes sujeitos na tentativa de manter equilíbrio emocional, evitando o aparecimento de sintomas ansiosos e de fracasso que possam levar ao sentimento de desesperança.

Os dados referentes à desesperança demonstram que $100 \%$ dos agentes penitenciários apresentam grau mínimo, ou seja, ante uma situação cotidiana que gere desconforto eles conseguem enfrentá-la sem perder a esperança ou a expectativa quanto ao futuro.

A desesperança pode ser considerada como um “... colapso mental com subcategorias implícitas, tais como: ausência de esperança, de desejo, percepção de estar sem possibilidades, ausência de significado na vida e ausência de energia" (Braga \& Cruz, 2005, p. 355). Segundo Stotland (1993 citado por Cunha, 2001, p. 6), a desesperança é "... como um sistema de esquemas cognitivos, nos quais o denominador comum é a expectativa negativa a respeito do futuro próximo e remoto", sendo considerada como nexo causal entre depressão e suicídio (Minkoff, Bergaman \& Beck, 1973 citados por Cunha 2001, p. 6).

Quanto a variável depressão, 100\% dos entrevistados apresentaram grau mínimo, ou seja, são capazes de aprender e experimentar o novo, denotando autoconfiança e autoestima no enfrentamento das situações cotidianas. "A autoestima de uma pessoa tem influência crucial em relação a seu comportamento, seu desenvolvimento, sua sensação de bem-estar, sua eficácia, seu nível de desempenho e suas relações com os outros" (Ramos \& Esper, 2007, p. 45).

Siqueira et al. (2009, p. 254) afirma que os sintomas da depressão são muito variados, variando de sensações de tristeza e pensamentos negativos a alterações da sensação corporal, como dores e enjoos. Todavia, é necessário um grupo de sintomas centrais para fazer o diagnóstico, como perda de energia ou interesse, humor deprimido, dificuldade de concentração, alterações do apetite e do sono, sentimento de pesar ou fracasso e lentidão das atividades físicas e mentais.

Constata-se também ausência de ideação suicida por parte dos agentes penitenciários entrevistados, fator este demonstrado pelo percentual negativo (100\%), o que é explicado pelo fato de as outras variáveis da saúde mental já expostas serem relativamente baixas ou ausentes entre os indivíduos pesquisados.

A ideação suicida, segundo Borges e Werlang (2006, p. 197), está relacionada a pensamentos e ideias de autodestruição, englobando desejos, atitudes ou planos para pôr fim à própria vida. Esse é um dos preditores para o risco de suicídio, podendo ser o primeiro passo para a sua efetivação. No entanto, não é o que os resultados da presente pesquisa demonstram, pois os sujeitos apresentam forte desejo de viver e diante de uma situação de risco de vida tentariam se salvar.

Um dos fatores que contribuem para os baixos resultados das escalas é a variável tempo de serviço exposta na Tabela 2, pois o tempo do exercício da atividade profissional dos sujeitos desta pesquisa é relativamente curto relacionado à pesquisa de Ramos e Esper (2007, p. 67), onde 93,93\% dos profissionais trabalham como agente penitenciário há mais de 10 anos. Para as autoras, o "excesso de trabalho trata-se de uma constante fonte de stress..." (Ramos \& Esper, 2007, p.47).

\section{Nível de estresse}

Para Margis, Picon, Cosner e Silveira (2003, p. 65), "a resposta ao estresse é resultado da

\footnotetext{
1 A noção de mecanismo de defesa engloba todos os meios utilizados pelo ego/eu para dominar, controlar, canalizar os perigos internos e externos (Doron \& Parot, 2000, p. 213).
}

Psicol. Argum. 2013 jul./set., 31 (74), 507-517 
interação entre as características da pessoa e as demandas do meio, ou seja, as discrepâncias entre o meio externo e interno e a percepção do indivíduo quanto à sua capacidade de resposta". 0 estresse no trabalho interfere nas relações de amizade, podendo gerar um círculo vicioso de proporções cada vez mais imprevisíveis (Correia, 2006, p. 40).

Lipp (2001, p. 20) define "estresse" como um processo de reação do organismo (componentes físicos e/ou psicológicos) causado pelas alterações psicofisiológicas que ocorrem quando o indivíduo se confronta com uma situação que o irrite, amedronte, excite ou o faça intensamente feliz. A mesma autora cita três fases do estresse propostas por Selye (1952): a primeira é a fase de alerta, quando o indivíduo se confronta com o estressor, quebrando a homeostase do organismo; quando o estressor é de longa duração ou sua intensidade é elevada o organismo tenta restabelecer o equilíbrio interno, adentrando na fase da resistência; a terceira é a fase de exaustão, que aparece quando a resistência do indivíduo não é suficiente para lidar com a fonte de estresse, ocorrendo a evolução do quadro. Lipp (2000, p. 11) sugere ainda uma quarta fase: a de quase exaustão, chamada assim por se encontrar entre a fase da resistência e da exaustão; caracteriza-se por enfraquecimento da pessoa, que não está mais conseguindo se adaptar ou resistir ao estressor; nessa fase, as doenças começam a surgir, porém não são tão graves quanto às da exaustão.

Para a obtenção dos dados referentes à variável estresse, utilizou-se o instrumento Inventário de Stress para Adultos de Lipp (ISSL), o qual avalia se há presença de estresse e a fase em que este se encontra.

A partir dos resultados expostos na Tabela 4, nota-se a ausência de estresse em 68,42\% dos agentes penitenciários. É natural e até esperado que o ser humano experimente algum desconforto ocasional, que se assemelha aos sintomas de estresse. Isso, isoladamente, não deve ser interpretado como tendo significado clínico para seu diagnóstico, o que sustenta um diagnóstico é o conjunto formado por vários itens que se prolongam por um período de tempo. No entanto, $31,57 \%$ da população pesquisada encontram-se na fase de resistência, na qual o organismo da pessoa resiste aos estressores e tenta restabelecer a homeostase. Quanto maior é o esforço que a pessoa faz para se adaptar e restabelecer a harmonia interior, maior é o desgaste do organismo, porém quando este consegue proceder a uma adaptação completa e resistir
Tabela 4 - Estresse

\begin{tabular}{lcc}
\hline Grau de estresse & Resultados & \\
& $\mathbf{n}$ & $\mathbf{\%}$ \\
\hline Sem estresse & 13 & 68,42 \\
Fase de alerta & - & - \\
Fase de resistência & 6 & 31,57 \\
Fase de quase exaustão & - & - \\
Fase de exaustão & - & - \\
\hline
\end{tabular}

Fonte: Dados da pesquisa.

ao estressor adequadamente, o processo do estresse é interrompido sem sequelas.

Em uma pesquisa realizada por Chies (2001 apud Lund et al., 2009, p. 3) no Presídio Regional de Pelotas, 73,33\% dos agentes penitenciários pesquisados afirmam sofrerem de alterações no seu comportamento, como maior grau de agressividade, de desconfiança, de nervosismo, de estresse e perda de paciência. O Sujeito 5 afirma: “... é estressante [o trabalho] mas me sinto melhor trabalhando do que ficar parado".

Para Lipp e Malagris (1995 citados por Fernandes et al., 2002, p. 814), “ ... o papel das horas totais semanais de trabalho evidencia que a atividade extra, remunerada, nas horas de folga, pode ser prejudicial para os agentes, provocando mais stress". Sendo assim, fez-se necessária a avaliação das atividades desempenhadas pelos sujeitos entrevistados nos seus dias de folga, as quais estão expostas na Tabela 5. As respostas foram obtidas mediante a aplicação do questionário.

Os resultados obtidos quanto às atividades desenvolvidas nos dias de folga revelam que $78,94 \%$ dos agentes penitenciários realizam atividades de entretenimento, 57,89\% preferem descansar, 15,78\% realizam serviços gerais não remunerados (trabalhar em casa e na lavoura), 10,52\% realizam trabalhos remunerados (motorista particular, construtor) e 10,52\% estudam nos dias de folga. Embora haja o trabalho remunerado entre as atividades realizadas nos dias de folga possivelmente para complementar a renda, a maioria dos agentes penitenciários desta pesquisa possuem tempo para entretenimento e descanso; diferentemente, na pesquisa de Fernandes et al. (2002, p. 811) realizada na Região Metropolitana de Salvador com 311 sujeitos, mais de um terço dos agentes penitenciários pesquisados realiza outras atividades remuneradas nos dias de folga e 13\% destes costumam dobrar o turno. 
Tabela 5 - Dados referentes às atividades desenvolvidas nos dias de folga

\begin{tabular}{lcc}
\hline & Resultados & \\
Atividades & $\mathbf{n}$ & \% \\
\hline Atividades de entretenimento & 15 & 78,94 \\
Descansar & 11 & 57,89 \\
Serviços gerais (não remunerado) & 3 & 15,78 \\
Trabalho remunerado & 2 & 10,52 \\
Estudar & 2 & 10,52 \\
\hline
\end{tabular}

Fonte: Dados da pesquisa.

Apesar de a maioria dos sujeitos desta pesquisa utilizar as horas de folga para entretenimento e descanso, a sobrecarga de trabalho devido à defasagem de funcionários e o convívio num ambiente atípico, como citado anteriormente, podem ter contribuído no aparecimento de sintomas de estresse, como exposto na Tabela 4. Embora esse não seja um quadro de estresse alarmante, é sinal de que algo está interferindo no equilíbrio interno desses sujeitos. Além disso, devido aos altos riscos expostos por seu trabalho, se deixado de lado, esses sintomas terão maior probabilidade de avançar para fases mais crônicas, nas quais o sujeito não consiga mais lidar com os fatores estressores do meio, sendo necessário o afastamento de seu ambiente de trabalho.

\section{Considerações finais}

O medo de ser rotulado por estar respondendo a um teste psicológico, entendido pelo senso comum como sendo medida de loucura e anormalidades, e a resistência ao conteúdo de algumas questões específicas dos instrumentos podem ter influenciado no desinteresse de alguns profissionais na participação da pesquisa.

... apesar do tempo de regulamentação e da proporção da categoria, o estereótipo clínico (aquele do divã) e a idéia de que 'psicólogo é médico de louco' ainda persistem no imaginário popular, distanciando sua imagem profissional de contextos menos conhecidos da sua atuação (Bley, 2007, pp. 25-26).

Embora quase todos os agentes penitenciários da instituição tenham aceitado participar da pesquisa, mostraram-se resistentes durante o processo de coleta de dados, sendo necessário ir até o local diversas vezes, pois sempre reportavam algum motivo para não responderem aos testes e, quando o faziam, ficavam constrangidos em relação a algumas questões dos instrumentos, principalmente as referentes a sexo (Inventário de Depressão e ISSL).

A resistência é em um mecanismo de defesa do ego que se opõe a qualquer força externa ameaçadora do equilíbrio interno, ou seja, é o instinto de autopreservação do indivíduo diante das situações que geram ansiedade. Portanto, a resistência na participação dos sujeitos é um acontecimento normal e até esperado, o que pode ter influenciado no resultado de alguns testes.

Os dados obtidos revelam que houve congruência entre os resultados dos testes, pois se a população em estudo indica não possuir desesperança, então estes provavelmente não desenvolverão depressão e menos ainda terão alguma ideação suicida. A depressão é o sinal de alerta para uma ideação suicida; não existindo a primeira, os índices de ideação são quase nulos. Quanto à ansiedade e ao estresse, é quase impossível não apresentar algum índice diante do ambiente em que esses sujeitos estão inseridos, todavia nesta pesquisa constatou-se que há ausência de sintomas patológicos na grande maioria dos participantes, o que pode ser indicativo de possível manipulação das respostas.

Portanto, percebe-se que os agentes penitenciários da instituição apresentam boas condições de saúde mental e baixos níveis de estresse, além de demonstrarem satisfação quanto à profissão que exercem, o que pode ser explicado pelo fato de os sujeitos possuírem pouco tempo de serviço, menos de cinco anos de exercício da profissão, evitando, assim, o aparecimento de sintomas ansiosos e de fracasso que possam levar ao sofrimento físico e mental.

Vale ressaltar que durante a coleta de dados ocorreu na instituição pesquisada uma tentativa de resgate, onde um dos agentes penitenciários foi mantido como refém, sofrendo alto teor de pressão psicológica, acarretando no afastamento do ambiente de trabalho. Esse acontecimento reforça a relevância deste estudo, uma vez que os sujeitos desempenham uma função de alto risco, expostos a diversas situações geradoras de estresse, o que pode lhes causar sofrimento psíquico.

Por meio desta pesquisa é notória a carência de funcionários nesse setor de segurança, o que acarreta no acúmulo de atividades e contratação de profissionais não preparados de forma adequada

Psicol. Argum. 2013 jul./set., 31 (74), 507-517 
para exercer as atividades próprias dos agentes penitenciários. Segundo relato do responsável pela instituição, o treinamento proporcionado a esses profissionais é muito precário, pois a teoria não consegue atender às demandas advindas da prática e apesar de esse treinamento se apresentar insuficiente, muitas vezes os agentes penitenciários vão para academia depois de já estarem trabalhando na instituição, pois há a urgência de pessoal que desempenhe a função desses profissionais.

Apesar de os resultados apontarem que há qualidade de saúde mental nos agentes penitenciários, sugere-se a reaplicação desta pesquisa em outros ambientes do sistema prisional brasileiro, para averiguar se essa é uma realidade peculiar da unidade pesquisada ou se os resultados se aplicam a outros contextos.

\section{Referências}

Bock, A. M. B., Furtado, O., \& Teixeira, M. L. T. (2002). Psicologias: Uma introdução ao estudo de Psicologia. (13. ed. rev. ampl.). São Paulo: Saraiva.

Borges, V. R., \& Werlang, B. S. G. (2006). Estudo de ideação suicida em adolescentes de 15 a 19 anos. Estudos de Psicologia, 11(3), 345-335.

Braga, C. G., \& Cruz, D. A. L. M. (2005). Sentimento de impotência: Diferenciação de outros diagnósticos e conceitos. Revista da Escola de Enfermagem da USP, 39(3), 350-357.

Bley, J. Z. (2007). Comportamento Seguro: Psicologia de segurança no trabalho e a educação para a prevenção de doenças e acidentes. (2. ed.). Curitiba: Sol.

Cipriano, D. G. I. (2004). Stress Feminino: Efeitos diferenciais do relacionamento afetivo. In M. E. N. Lipp (Org.). Stress no Brasil: Pesquisas avançadas (pp. 161168). Campinas: Papirus.

Correia, A. P. (2006). Uma análise dos fatores de risco da profissão do agente penitenciário: Contribuições para uma política de segurança e saúde na gestão penitenciária. Monografia de Especialização em Gestão Penitenciária Problemas e desafios, Universidade Federal do Paraná, Curitiba. Recuperando em 16 nov. 2009, dehttp://www.depen.pr.gov.br/arquivos/File/ ademildo_\%20passos_correia2006.pdf

Cunha, J. A. (2001). Manual da versão em português das Escalas Beck. São Paulo: Casa do Psicólogo.
Doron, R., \& Parot, F. (2000). Dicionário de Psicologia. São Paulo: Ática.

Fernandes, R. C. P., Silvany Neto, A. M., Sena, G. M., Leal, A. S., Carneiro, C. A. P., \& Costa, F. P. M. (2002). Trabalho e cárcere: Um estudo com agentes penitenciários da Região Metropolitana de Salvador, Brasil. Caderno de Saúde Pública, 18(3), 807-816.

Hanns, L. A. (1996). Dicionário comentado do Alemão de Freud. Rio de Janeiro: Imago.

Lei n. 7210, de 11 de julho de 1984 (1984). Institui a Lei de Execução Penal. Brasília. 1984. Recuperado em 22 jul. 2010, de http://www.jusbrasil.com.br/ legislacao/109222/lei-de-execucao-penal-lei- 7210-84

Lei n. 10.216, de 6 de abril de 2001 (2001). Dispõe sobre a proteção e os direitos das pessoas portadoras de transtornos mentais e redireciona o modelo assistencial de saúde mental. Brasília. 2001. Recuperado em 22 jul. 2010, de http://www.planalto.gov.br/ccivil_03/leis/leis_2001/l10216.htm

Lancman, S., Sznelwar, L. I., \& Jardim, T. A. (2006). Sofrimento psíquico e envelhecimento no trabalho: Um estudo com agentes de trânsito. Revista de Terapia Ocupacional da Universidade de São Paulo, 17(3), 129-136. Recuperado em 22 jan. 2010, de http://www.crefito.com.br/revista/TO/2006-3/09\%20p.129-136.pdf

Lipp, M. E. N. (2000). Manual do inventário de sintomas de stress para adultos de Lipp (ISSL). São Paulo: Casa do Psicólogo.

Lipp, M. E. N. (2001). Stress: Conceitos básicos. In: M. E. N. Lipp (Org.). Pesquisas sobre stress no Brasil: Saúde, ocupações e grupos de risco. (2. ed., pp. 17-31). Campinas: Papirus.

Lopes, R.. (2002). Psicologia jurídica - O cotidiano da violência: 0 trabalho do agente de segurança penitenciária nas instituições prisionais. Revista Eletrónica Internacional de la Unión Latinoamericana de Psicología. Recuperado em 19 set. 2013, de http:// www.psicolatina.org/00/juridica.html

Lund, D. G., Nedel, A. P., Nedel, F., Biguetti, T. I., \& Castilhos, E. D. (2009). Avaliação do estresse e da disfunção-crânio-mandibular nos agentes penitenciários do Presídio Estadual de Canguçu-RS. Anais do Congresso de Iniciação Científica 18., Encontro de Pós-Graduação 11., Mostra Científica 1. da Universidade Federal de Pelotas. Pelotas. Recuperado em 18 fev. 2010, de http://www.ufpel.tche.br/cic/2009/ cd/pdf/CS/CS_01912.pdf 
Margis, R., Picon, P., Cosner, A. F., \& Silveira, R. O. (2003). Relação entre estressores, estresse e ansiedade. Revista de Psiquiatria do Rio Grande do Sul, 25(Suppl.1), 65-74. Recuperado em 18 fev. 2010, de http://www.scielo.br/scielo.php?pid=S0101$-81082003000400008 \&$ script $=$ sci_arttext

Mendoza, R., Medeiro, V., \& Costa, J. B. (2007). Comprometimento organizacional, fatores estressantes do trabalho e identidade social: Um estudo exploratório. Revista de Ciências Humanas e Artes, 13(1), 92-100. Recuperado em 18 fev., 2010, de http://www.ch.ufcg. edu.br/arius/01_revistas/v13n1/09_arius_13_1_comprometimento_organizacional_fatores_estressantes_ do_trabalho_e_identidade_social.pdf

Minayo, M. C. S. (Org.). (2008). Pesquisa social: Teoria, método e criatividade. (27. ed.). Petrópolis: Vozes.

Organização Mundial da Saúde. (2002). Relatório Mundial da Saúde. Saúde Mental: Nova concepção, nova esperança. Lisboa: Direção-Geral da Saúde. Recuperado em 20 nov. 2009, de http://www.who.int/whr/2001/ en/whr01_djmessage_po.pdf

Ramos, E. C., \& Esper, M. H. (2007). Síndrome de Burnout na penitenciária feminina de regime semi-aberto. Projeto de Conclusão de Curso Administração, Faculdade Anchieta de Ensino Superior do Paraná, Curitiba. Recuperado em 20 jan. 2010, de http:// www.depen.pr.gov.br/arquivos/File/monografia_ellen_mara.pdf

Rezende Neto, A. (2004). Gerenciamento do stress: Controle da ansiedade e das alterações fisiológicas. In M. E. N. Lipp (Org.). O stress no Brasil: Pesquisas avançadas. (pp. 93-104). Campinas: Papirus.

Rocha, E. R. (2003). A motivação do agente penitenciário para o trabalho. Projeto de Conclusão de Curso de Especialização em Modalidades de Tratamento Penal e Gestão Prisional, Universidade Federal do Paraná, Curitiba. Recuperado em 15 jan. 2010, de http:// www.depen.pr.gov.br/arquivos/File/monografia_ edinilson.pdf
Rosa, C. F. S. C. (2007). Saúde mental em contexto migratório: Um estudo na região de Lisboa. Dissertação de Mestrado em Relações Interculturais, Universidade Aberta, Lisboa. Recuperado em 15 jan. 2010, de https://repositorioaberto.uab.pt/bitstream/10400.2/ 638/1/LC383.pdf

Rumin, C. R. (2006). Sofrimento na vigilância prisional: 0 trabalho e a atenção em saúde mental. Psicologia: Ciência e Profissão, 26(4), 570-581. Recuperado em 15 fev., 2010, de http://www.scielo.br/pdf/pcp/ v26n4/v26n4a05.pdf

Sadock, B. J., \& Sadock, V. A. (2007). Compêndio de Psiquiatria: Ciência do Comportamento e Psiquiatria Clínica. (9. ed.). Porto Alegre: Artmed.

Santos, J. R. R. (2007). O fenômeno da prisionização em agentes penitenciários do estado do Paraná. Monografia de Especialização em Gestão Penitenciária, Universidade Federal do Paraná, Curitiba. Recuperado em 20 jan. 2010, de http://www.depen.pr.gov.br/arquivos/File/ JOSE_\%20ROBERTO_\%20SANTOS2007.pdf

Silva, M. R. S. N (2011). O papel do agente penitenciário na prevenção da violência e promoção de direitos humanos. Recuperado em 19 set. 2013, de http://agepensczs.blogspot.com.br/2011/04/o-papel-do-agente-penitenciario-na.html

Siqueira, G. R., Vasconcelos, D. T., Duarte, G. C., Arruda, I. C., Costa J. A. S., \& Cardoso, R. O. (2009). Análise da sintomatologia depressiva nos moradores do abrigo Cristo Redentor através da aplicação da Escala de Depressão Geriátrica (EDG). Ciência \& Saúde Coletiva, 14(1), 252-259. Recuperado em 15 jan. 2010, de http:// www.scielo.br/scielo.php?script=sci_arttext\&pid= S1413-81232009000100031\&lng=pt

Zanin, J. E., \& Oliveira, R. C. S. (2006). Penitenciárias privatizadas: Educação e ressocialização. Práxis Educativa, 1(2), 39-48. Recuperado em 20 fev. 2010, de http:// www.revistas2.uepg.br/index.php/praxiseducativa/ article/viewArticle/284 